\title{
PHYLOGENETIC ANALYSIS OF EQUINE HERPES VIRUS 4 GLYCOPROTEINS IN COMPARISON TO EQUINE ABORTION VIRUS
}

\author{
HASSAN Y.A.H. MAHMOUD ${ }^{1}$, ALSAGHER O. ALI ${ }^{1}$ and AHMED EZZAT AHMED ${ }^{2}$ \\ 1 Division of Infectious Diseases, Department of Animal Medicine, Faculty of Veterinary Medicine, South Valley \\ University, Qena 83523, Egypt. \\ ${ }^{2}$ Department of Theriogenology, Faculty of Veterinary Medicine, South Valley University, 83523 Qena, Egypt.
}

Received: 21 February 2017; Accepted: 20 March 2017

\begin{abstract}
Equine Herpes Virus-1(EHV-1) and 4 (EHV-4), both viruses are found in horse populations all over the world and leading to a feverish respiratory disease per annum among horses in areas with intense horse populations. Abortion in mares infection with EHV-4 was rarely, from another side mare may abort several weeks to months after clinical or subclinical infection with EHV-1. Nucleotide sequences of EHV-4 genes encoding each glycoprotein showed that the amino acid sequences ( $\mathrm{gB}, \mathrm{gE}, \mathrm{gG}, \mathrm{gH}, \mathrm{gK}, \mathrm{gL}, \mathrm{gM}$ and $\mathrm{gN}$ of TH20p) resemble that of the reference genome (NS80567) except (gC, gD, gI and gP2) at certain positions. By constructing phylogenetic tree using glycoproteins sequences of EHV-4, EHV-4 reference genome and EHV-1 (strain $89 \mathrm{c} 25 \mathrm{p}$ ) revealed that there are two main clusters within each clusters.
\end{abstract}

Key words: Equine, Abortion, EHV-1, EHV-4, Phylogenetic analysis

\section{INTRODUCTION}

Equine herpesvirus 1 and 4 are a members of genus Varicellovirus, Alphaherpesvirinae subfamily (Roizman, 1996; Davison et al., 2009). Equine herpesvirus-1 (EHV-1) is an important, ubiquitous equine viral pathogen that exerts its major impact by inducing abortion in pregnant mares, early neonatal death, respiratory disease in foals and myeloencephalopathy (Reed and Toribio, 2004; Patel and Heldens, 2005). The complete genome sequences of EHV-4 was reported and that the virus has a linear double stranded DNA (Cullinane et al., 1988; Roizman et al., 1992; Telford et al., 1998). Sequence analysis showed that there is $(55-84 \%)$ DNA homology depending on the gene and that the homology at the amino acid level ranged from 55\% to $96 \%$ (Telford et al., 1998). The EHV-4 mainly causes respiratory disease in horse and rarely causes abortion, while the EHV-1 primarily causes abortion and myeolo-encephalopthy in addition to respiratory disease (Slater et al., 1994). Both EHV-4 and EHV-1 cause economic losses and negative impact on equine as a result of morbidity or mortality from virus-

Corresponding author: Dr. HASSAN Y.A.H. MAHMOUD

E-mail address: mhassan@vet.svu.edu.eg

Present address: Division of Infectious Diseases, Department of Animal Medicine, Faculty of Veterinary Medicine, South Valley University, Qena 83523, Egypt. induced abortion and respiratory disease. However, EHV-4-specific vaccine has not been available, EHV1 and EHV-4 have resistant reactions and build latent infection, there are contrasts concerning infection section and their capacity to meddle with the intrinsic insusceptible reaction (Ma,G. et al., 2013).

\section{MATERIALS AND METHODS}

\section{1 - Cells}

FHK-Tcl3.1 (Maeda et al., 2007; Andoh et al., 2009) and 293T cells were maintained in Dulbecco's modified Eagle's medium (GIBCO) supplemented with $10 \%$ heat-inactivated fetal calf serum (FCS; JR Scientific, Woodland, CA, U.S.A.), 100 units $/ \mathrm{ml}$ penicillin and $100 \mu \mathrm{g} / \mathrm{ml}$ streptomycin (GIBCO) at $37^{\circ} \mathrm{C}$ with $5 \% \mathrm{CO} 2$.

\section{2 - Viruses}

EHV-4 TH20 strain was isolated from a colt suffering from respiratory disease at1952 (Kawakami et al., 1962) was plaque-purified three times in primary fetal horse kidney (FHK) cells and termed as TH20p.

\section{3 - Construction of expression plasmids}

For expression of glycoproteins of EHV-4 each gene was amplified from the genome of EHV -4 TH20p by 
polymerase chain reaction (PCR) using primers (Table 1). PCR was performed by using Takara LA PCR Kit Ver. 2.1 (Takara), and the amplified fragments were digested with restriction enzymes, and were then cloned into the expression plasmid pCAGGS, which was kindly provided by Dr. Miyazaki (Osaka University). The nucleotide sequences of at least two constructed plasmids were determined using a Big Dye Terminator v3.1 kit (Applied Biosystems). All plasmids were purified by QIAprep Spin Miniprep Kit (QIAGEN) or QIAfilter plasmid Midi Kit (QIAGEN) (Mahmoud, 2013).

\section{4 - Bioinformatics analysis}

Sequence alignments, translations, and comparisons were carried out using BIOEDIT (Version 7.0.9.0, Hall, T.A, 1999). The BLAST algorithm was used to search the NCBI Gen Bank (http://www.ncbi. nlm.hih.gov/) databases for homologous sequences. Neighbor-joining trees (Saitou and Nei, 1987) were constructed on the basis of genetic distances, estimated by Kimura's (1980) two-parameter method, using MEGA 5 (Kumar et al., 2001; http://www.megasoftware.net). The reliability of the trees was estimated by bootstrap confidence values (Felsenstein, 1985) and 500 bootstrap replications were used.

\section{RESULTS}

\section{1 - Sequence analysis of each glycoprotein of EHV- 4 strain TH20p}

Nucleotide sequences of genes encoding each glycoprotein showed that the amino acid sequences of $\mathrm{gB}, \mathrm{gE}, \mathrm{gG}, \mathrm{gH}, \mathrm{gK}, \mathrm{gL}, \mathrm{gM}$ and $\mathrm{gN}$ of TH20p were identical to those of NS80567, but those of $\mathrm{gC}, \mathrm{gD}, \mathrm{gI}$ and gp2 were different at positions 309 (Aspartic acid to Glutamic acid), 27 and 382 (leucine to valine and glycine to glutamic acid, respectively), 134 and 298 (arginine to tryptophan and aspartic acid to alanine, respectively) and 376, 463 and 509 (leucine to serine, lysine to arginine and Glutamine to Arginine, respectively), respectively.

\section{2 - Phylogenetic analysis of EHV4 glycoproteins in relation with strain NS80567 and EHV-1}

The EHV4 glycoproteins are grouped in 3 different clusters; the first cluster (gC4, gP24, gH4 and $\mathrm{gK} 4$ ), the second cluster (gE4, gL4, gI4 and gM4) and the third one (gG4, gB4, gD4 \&gN4) (Fig. 1).By constructing a tree containing the glycoproteins of EHV4, EHV4 reference strain (NS80567) and EHV-1 revealed that there are two main clusters within each clusters, each glycoprotein of the EHV-4 are grouped together except glycoprotein D (gD_EHV-1) (Fig. 1). The evolutionary history (Fig. 2) was inferred using the Minimum Evolution Method (Rzhetsky and Nei, 1992). The optimal tree with the sum of branch length $=19.96041633$ is shown. The percentage of replicate trees in which the associated taxa clustered together in the bootstrap test (500 replicates) are shown next to the branches (Felsenstein, 1985). The evolutionary distances were computed using the Poisson correction method (Zuckerkandl and Pauling, 1965). The ME tree was searched using the Close-NeighborInterchange (CNI) algorithm at a search level of 1 (Nei and Kumar, 2000). The Neighbor-joining algorithm was used to generate the initial tree (Saitou and Nei, 1987). The analysis involved 36 amino acid sequences. All positions containing gaps and missing data were eliminated; there were a total of 102 positions in the final dataset evolutionary analyses were conducted in MEGA6 (Tamura et al., 2013). Evolutionary pressures on proteins are frequently measured by the ratio of substitution rates at nonsynonymous and synonymous sites. The dN/dSratio was first established for application to distantly diverged sequences, the alterations among which represent substitutions that have fixed along independent lineages, the $\mathrm{dN} / \mathrm{dS}$ ration is greater than 1 , so the sites are under positive or diversifying selection (Tabel 2). Diagrammatic representation of EHV4 glycoproteins in comparison with the reference strain (accession number AF030027) through using an online program (https://server.gview.ca/job/ 350CA7A8BCAE7E9A5F5CB572551A7348/results Fig. 3) 
Table 1: Primers based on the complete genome of EHV-4 NS80567

\begin{tabular}{|c|c|c|}
\hline \multirow[t]{2}{*}{ Genes } & \multicolumn{2}{|r|}{ Primers } \\
\hline & Name & Sequences ${ }^{a}$ \\
\hline \multirow[t]{2}{*}{$\mathrm{gB}$} & $\mathrm{F}$ & $5^{\prime}$-ACGAATTCatgtccacttgttgccgtgc-3' \\
\hline & $\mathrm{R}$ & $5^{\prime}$-ACCTCGAGttaaaccattttttcgetttcca-3' \\
\hline \multirow[t]{2}{*}{$\mathrm{gC}$} & $\mathrm{F}$ & 5'-ACGAATTCatgggtttggtaaatataatgcg-3' \\
\hline & $\mathrm{R}$ & $5^{\prime}$-ACCTCGAGttagaagtctgctttcttgtac-3’ \\
\hline \multirow[t]{2}{*}{$\mathrm{gD}$} & $\mathrm{F}$ & $5^{\prime}$-ACAGATCTatgtctaccttcaagcctatg-3' \\
\hline & $\mathrm{R}$ & $5^{\prime}$-ACCTCGAGttacggaagctgagtatatttg-3’ \\
\hline \multirow[t]{2}{*}{$\mathrm{gE}$} & $\mathrm{F}$ & $5^{\prime}$-ACAGATCTatggagctgttagactcccgc-3' \\
\hline & $\mathrm{R}$ & 5'-ACCTCGAGtcattttaggatagacctgagc-3’ \\
\hline \multirow[t]{2}{*}{$\mathrm{gG}$} & $\mathrm{F}$ & $5^{\prime}$-ACAGATCTatgttggctgtgggagcaact-3’ \\
\hline & $\mathrm{R}$ & $5^{\prime}$-ACCTCGAGttatgcaacgtactcaagtcg-3' \\
\hline \multirow[t]{2}{*}{$\mathrm{gH}$} & $\mathrm{F}$ & $5^{\prime}$-ACGAATTCatgtcacaaccgtatctaaaaat-3' \\
\hline & $\mathrm{R}$ & 5'- ACCTCGAGttactcagagtttaataacaaact-3 \\
\hline \multirow[t]{2}{*}{$\mathrm{gI}$} & $\mathrm{F}$ & $5^{\prime}$-ACGAATTCatggccaaacatactgtattgt-3 \\
\hline & $\mathrm{R}$ & $5^{\prime}$-ACCTCGAGttagtcttcctcttttatggcc-3' \\
\hline \multirow[t]{2}{*}{$\mathrm{gK}$} & $\mathrm{F}$ & 5'-ACAGATCTatgttattcggggggagaacg-3’ \\
\hline & $\mathrm{R}$ & $5^{\prime}$-ACGCATGCttattgtgacaaggactcgecc-3’ \\
\hline \multirow[t]{2}{*}{$\mathrm{gL}$} & $\mathrm{F}$ & $5^{\prime}$-ACAGATCTatgtatcactcccaattgggtg-3 \\
\hline & $\mathrm{R}$ & $5^{\prime}$-ACCTCGAGtcattctgaagtttcttgaatt-3’ \\
\hline \multirow[t]{2}{*}{$\mathrm{gM}$} & $\mathrm{F}$ & $5^{\prime}$-ACAGATCTatggcacgacgtggcgctgct-3’ \\
\hline & $\mathrm{R}$ & $5^{\prime}$-ACCTCGAGTtaacggtaatctctgcgcgag-3` \\
\hline \multirow[t]{2}{*}{$\mathrm{gN}$} & $\mathrm{F}$ & $5^{\prime}$-ACAGATCTatgttgtcagcgagattagtg-3’ \\
\hline & $\mathrm{R}$ & $5^{\prime}$-ACCTCGAGtcagtgtaggtgtcgcaacat-3’ \\
\hline \multirow[t]{2}{*}{$\mathrm{gp} 2$} & $\mathrm{~F}$ & $5^{\prime}$-ACAGATCTatggggttcatctatgttagc-3' \\
\hline & $\mathrm{R}$ & 5'-ACCTCGAGttaatatacggacgcccgggg-3’ \\
\hline
\end{tabular}

position of genome of Equine herpesvirus 4 strain NS80567, complete genome (Accession No. AF030027.1) a: Capital letters indicate the restriction endonuclease digestion site and additional two nucleotides.

Table 2: Estimates of Average Codon-based Evolutionary Divergence over all Sequence Pairs

\begin{tabular}{ccccccccc}
\hline Non-Synonymous sub. & Synonymous sub. & \multicolumn{2}{c}{ dN-dS } & & dS-dN & dN/dS \\
\hline dN & SE & dS & SE & value & SE & value & S.E. & 1.001 \\
\hline 2.269 & 0.084 & 2.266 & 0.078 & 0.191 & 0.176 & -0.191 & 0.176 \\
\end{tabular}




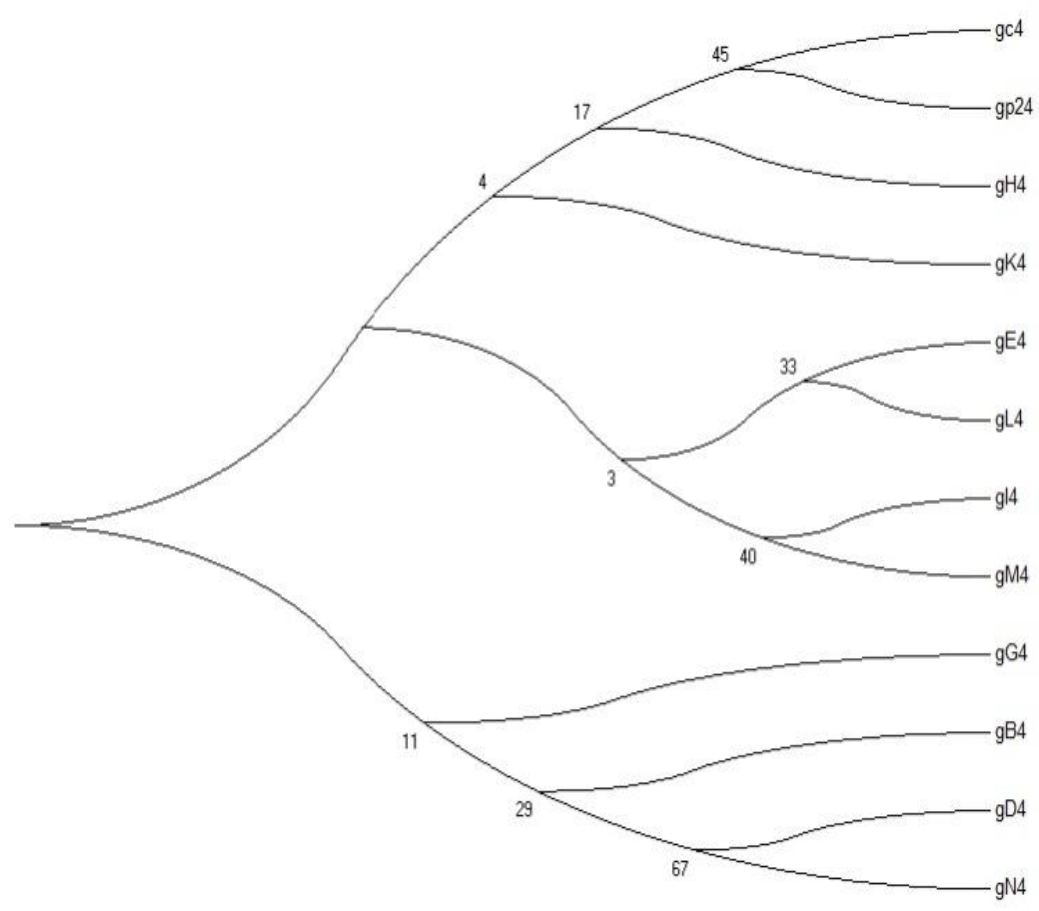

Figure 1: Neighbor joining tree showing the relationship between different glycoprotein of EHV4.

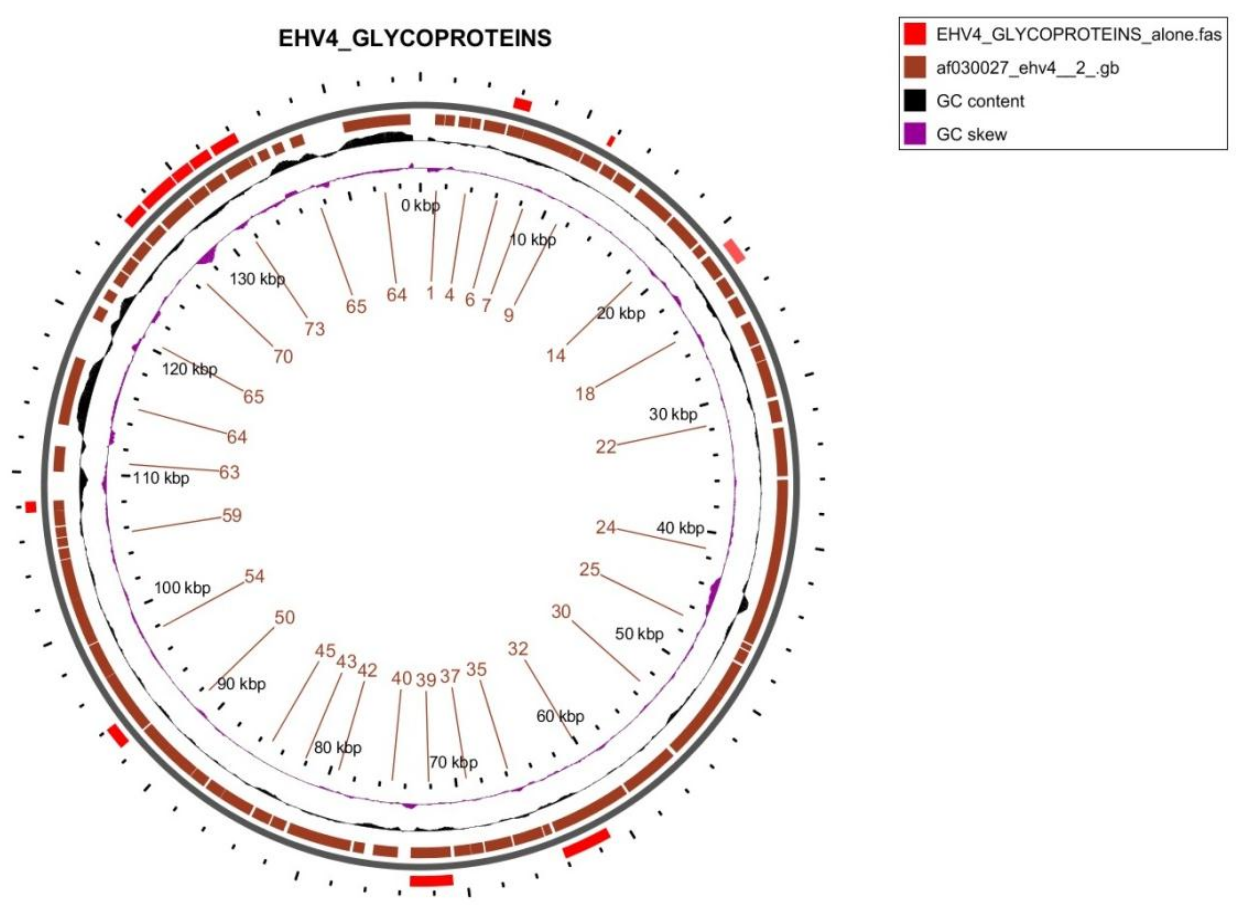

Figure 2: The BLAST Atlas analysis type displays regions of the uploaded glycoproteins sequences where there are BLAST hits to the reference genome. 


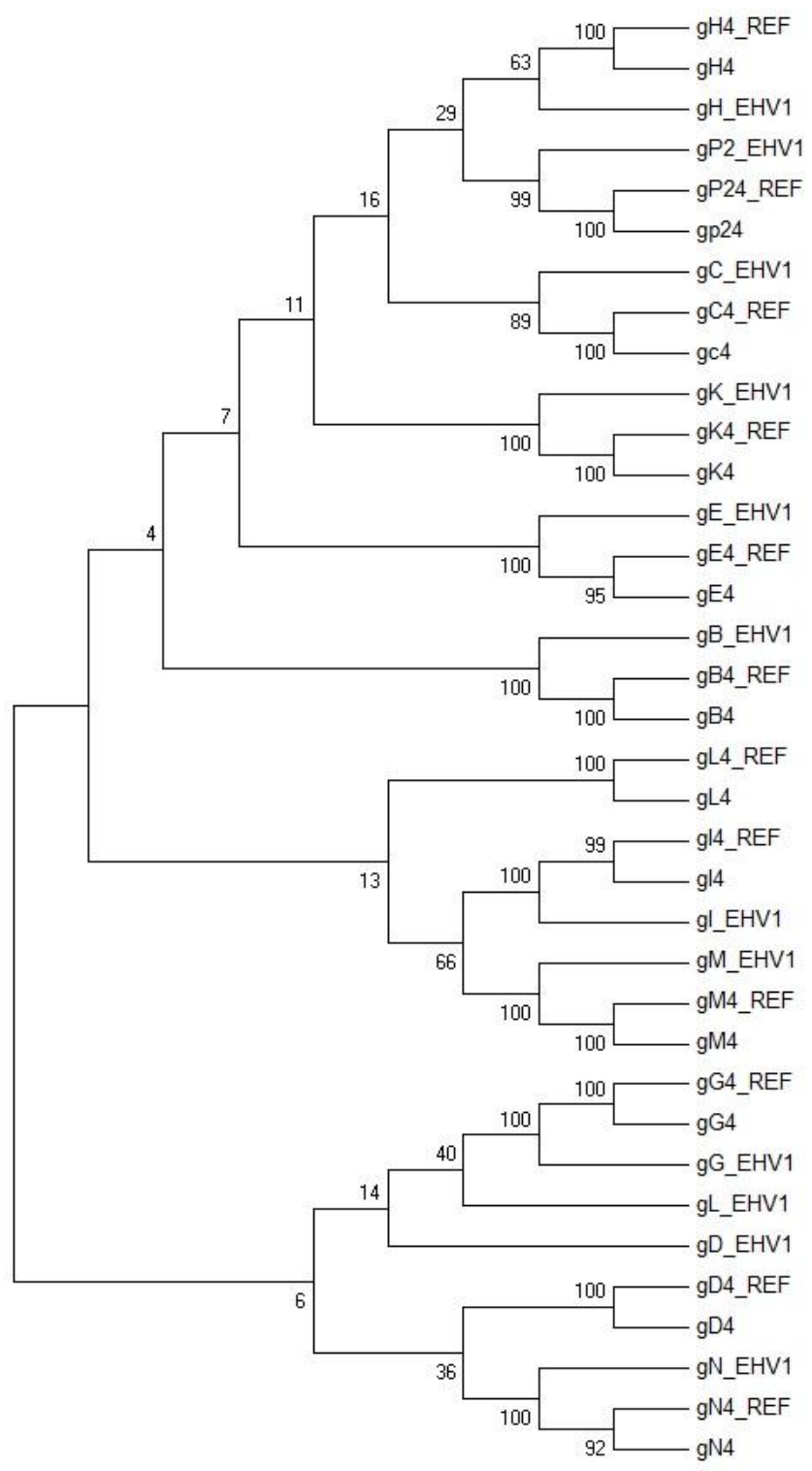

Figure 3: Neighbor joining tree showing the relationship between different glycoprotein of EHV-4 and EHV-1.

\section{DISCUSSION}

Viral glycoproteins play important roles in the biology of herpesviruses, envelope glycoproteins of EHV-4 encodes 12 different glycoproteins, which are involved in virus attachment, penetration and egress, cell to-cell spread as well as pathogenicity and virulence. The result of sequence analysis of amino acid EHV-4 strain TH20p indicated that there is no difference in amino acid for $\mathrm{gH}, \mathrm{gk}, \mathrm{gM}$ and $\mathrm{gN}$ comparing to reference strain NS80567 of EHV-4. The rapid accumulation of DNA sequences provides increased opportunities to study molecular evolution and phylogenetic relationships many methods were used to constructphylogenetic trees for organisms, based on the introduction of alignment of DNA or proteinhomologous sequences, followed by tree construction based on various statistical criteria such as maximum likelihood, parsimony, distance matrices, paralinear distances and invariants. The pattern of nucleotide substitution within the different glycoproteins was examined, the overall average value for the number of synonymous nucleotide substitution (ds) per site and the number of nonsynonymous nucleotide substitution $(\mathrm{dn})$ per site were calculated separately for the EHV-4 glycoproteins. The result of nonsynonymous substitutions was slightly higher than that of synonymous substitutions (Table 2), this result indicates slightly diversifying selection or positive selection working on these glycoproteins (Nei and Gojobori, 1986; Tamura et al., 2013). The phylogenetic Neighbor-joining trees (Saitou and Nei, 1987) were constructed on the basis of genetic distances (Kimura, 1980) two-parameter 
method by using MEGA 6 (Tamura et al., 2013) for the 12 glycoproteins of EHV4 (Fig. 1-2) and 36 glycoproteins of EHV4, EHV4 reference strain (NS80567) and EHV-1 (Fig. 3). These trees revealed that these similarities between glycoproteins may be due to the pathogen which could provide selection pressure to keep specific MHC alleles which is necessary to face a specific immune response to a common pathogen (Zhou and Hickford, 2004), or from a common ancestor. These alleles predate speciation according to the trans-species hypothesis (Klein et al., 1998) who argued that over evolutionary time a group of ancestral alleles were passed on to a species' descendants, while mutations accumulate further through time.

\section{CONCLUSION}

The non-synonymous substitutions were slightly higher than that of synonymous substitutions; this result indicates slightly diversifying selection or positive selection working on these glycoproteins.

\section{ACKNOWLEDGEMENTS}

Hassan, Y.A.M. received financial support in the form of post doctor scholarship from the Egyptian government.

\section{REFERENCES}

Andoh, K.; Kai, K.; Matsumura, T. and Maeda, K. (2009): Further development of an equine cell line that can be propagated over 100 times. J. Equine Sci. 20, 11-14.

Colle, C.F.III. and O'Callaghan, D.J. (1995): Transcriptional analyses of the unique short segment of EHV-1 strain Kentucky A. Virus Genes 9, 257-268.

Cullinane, A.A.; Rixon, F.J. and Davison, A.J. (1988): Characterization of the genome of equine herpes virus 1 subtype 2. J. Gen. Virol. 69, 1575-1590.

Davison, A.J.; Eberle, R.; Ehlers, B.; Hayward, G.S.; McGeoch, D.J.; Minson, A.C.; Pellett, P.E.; Roizman, B.; Studdert, M.J. and Thiry, E. (2009): The order Herpesvirales. Arch. Virol. 154, 171-177.

Damiani, A.M.; Matsumura, T.; Yokoyama, N.; Maeda, K.; Miyazawa, T.; Kai, C. and Mikami, T. (1998): Nucleotide sequences of glycoprotein I and $\mathrm{E}$ genes of equine herpesvirus type 4. J. Vet. Med. Sci. 60, 219 225.

Felsenstein, J. (1985): Confidence limits on phylogenies: An approach using the bootstrap. Evolution 39, 783-791.
Hassan Y.A.H. Mahmoud. (2013): Studies on Glycoproteins of Equine Herpesviruses. PhD thesis, Yamaguchi University, Japan 2013.

Hall TA. BioEdit (1999): A user-friendly biological sequence alignment editor and analysis program for Windows 95/98/ NT. Nucleic Acids Symp. Ser. 1999; 41: 95-98.

Hickford, J.G.; Zhou, H.; Slow, S. and Fang, Q. (2004): Diversity of the ovine DQA2 gene. J. Anim. Sci. 82, 1553-1563.

Kawakami, Y.; Kaji, T.; Ishizaki, R.; Shimizu, T. and Matumoto, M. (1962): Etiologic study on an outbreak of acute respiratory disease among colts due to equine rhinopneumonitis virus. Jpn. J. Exp. Med. 32, 211-229.

Kimura, M. (1980): A simple method for estimating evolutionary rates of base substitutions through comparative studies of nucleotide sequences: J. Mol. Evol., 16, 111-120.

Kumar, S. and Gadagkar, S.R. (2001): Disparity Index: A simple statistic to measure and test the homogeneity of substitution patterns between molecular sequences. Genetics 158:1321-1327.

Klein, J.; Sato, A.; Nagl, S. and O'hUigin, C. (1998): Molecular trans-species polymorphism.: Annu. Rev. Ecol. Syst., 29, 1-21.

Maeda, K.; Yasumoto, S.; Tsuruda, A.; Andoh, K.; Kai, K.; Otoi, T. and Matsumura, T. (2007): Establishment of a novel equine cell line for isolation and propagation of equine herpesviruses. J. Vet. Med. Sci., 69, 989-991.

Nei, M. and Gojobori, T. (1986): Simple methods for estimating the numbers of synonymous and non-synonymous nucleotide substitutions. Molecular Biology and Evolution 3, 418-426.

Nei, M. and Kumar, S. (2000): Molecular Evolution and Phylogenetics. Oxford University Press, New York.

Ma, G.; Azab, W. and Osterrieder, N. (2013): Equine herpesviruses type 1 (EHV-1) and 4 (EHV-4) masters of co-evolution and a constant threat to equids and beyond. Vet. Microbiol. 29;167(1-2): 123-34.

Patel, J.R. and Heldens, J. (2005): Equine herpes viruses 1 (EHV-1) and 4 (EHV-4) epidemiology, disease and immunoprophylaxis: a brief review. The Veterinary Journal 170, 14-23.

Reed, S.M. and Toribio, R.T. (2004): Equine herpes virus 1 and 4 . Veterinary Clinics of North America Equine Practice 20, 631-642.

Roizman, B. (1996): Herpes viridae, In Virology (3rd Edn.), Field, B.N; Knipe, D.M; Howley, P.M; Channock, R.M; Melnick, J.L; Monath, T.P; Roizman, B; Straus, S.E (Eds.), LippincottRaven, Philadelphia, PA. PP: 2221-2230.

Roizmann, B.; Desrosiers, R.C.; Fleckenstein, B.; Lopez, C.; Minson, A.C. and Studdert, M.J. (1992): The family Herpes viridae: an update. The Herpesvirus Study Group of the 
International Committee on Taxonomy of Viruses. Arch Virol., 123, 425-49.

Rudolph, J. and Osterrieder, N. (2002a): Equine herpesvirus type 1 devoid of $\mathrm{gM}$ and gp2 is severely impaired in virus egress but not direct cell-to-cellspread. Virology 293, 356367.

Rzhetsky, A. and Nei, M. (1992): A simple method for estimating and testing minimum evolution trees. Molecular Biology and Evolution 9, 945-967.

Saitou, N. and Nei, M. (1987): The neighbor-joining method: A new method for reconstructing phylogenetic trees. Molecular Biology and Evolution, 4, 406-425.

Slater, J.D.; Baxi, M.; Tewari, D.; Gibson, J.; Field H.J.; Ludwig, H.; Steinbach, F. and Borchers, $K$. (1994): Experimental infection of specific pathogen free ponies with equid herpesvirus1: detection of infectious virus and viral DNA. In: NAKAJIMA, H. \& PLOWRIGHT, W., (eds). Equine Infectious Diseases VII. Newmarket (Suffolk): R \& W Publications, pp. 255-260.
Tamura, K.; Stecher, G.; Peterson, D.; Filipski, A. and Kumar, S. (2013): MEGA6: Molecular Evolutionary Genetics Analysis version 6.0. Molecular Biology and Evolution, 30, 2725 2729

Telford, E.A.; Watson, M.S.; Perry, J.; Cullinane, A.A. and Davison, A.J. (1998): The DNA sequence of equine herpesvirus-4. J. Gen. Virol., 79, 1197-1203.

Tischer, B.K.; Schumacher, D.; Messerle, M.; Wagner, M. and Osterrieder, N. (2002): The products of the UL10 (gM) and the UL49.5 genes of Marek's disease virus serotype 1 are essential for virus growth in cultured cells. J. Gen. Virol. 83, 997-1003.

Zhou, H. and Hickford, J.G. (2004): Allelic polymorphism in the ovine DQA1 gene. J. Anim. Sci. 82:8.-16.

Zuckerkandl, E. and Pauling, L. (1965): Evolutionary divergence and convergence in proteins. Edited in Evolving Genes and Proteins by V. Bryson and H.J, Academic Press, New York, Vogel., PP: 97-166.

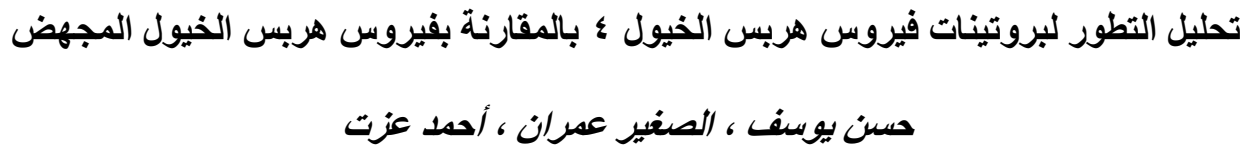

Email: mhassan@vet.svu.edu.eg Assiut University web-site: www.aun.edu.eg

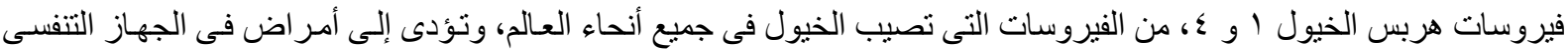

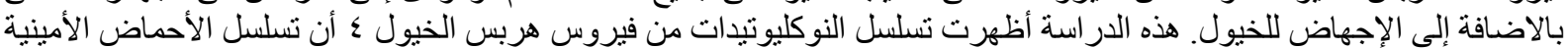
لكل من البروتينات السكرية (TH20p) في العتره المعزولة (TH, gE, gE, gG, gH, gK, gL, gM and gN) متشابه مع العتره

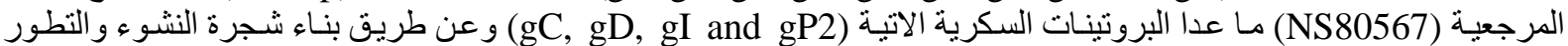

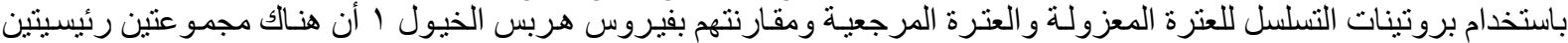

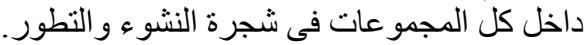

